\title{
ERRATUM
}

A. J. Plater - J. F. Boyle $\cdot$ C. Mayers

S. D. Turner - R. W. Stroud

\section{Climate and human impact on lowland lake sedimentation in Central Coastal California: the record from C. 650 AD to the present}

Published online: 3 May 2006

(C) Springer-Verlag 2006

\section{Reg Environ Change (2006) 6(1-2):71-85}

The authors wish to draw attention to the fact that a previous version of the pollen diagram for core PL2001 was published in error as Fig. 2b in Plater et al. (2006) 'Climate and human impact on lowland lake sedimentation in Central Coastal California: the record from c. $650 \mathrm{AD}$ to the present'. This incorrectly presents relative pollen percentages for Tsuga. The authors emphasise that there is no palynological evidence for the presence of Tsuga in the region of Pinto Lake in Central Coastal California prior to the 20th Century, and that the interpretations given in the original text are based on the diagram presented below.

The online version of the original article can be found at http:// dx.doi.org/10.1007/s10113-006-0013-1

\footnotetext{
A. J. Plater $(\bowtie) \cdot$ J. F. Boyle $\cdot$ C. Mayers

Department of Geography, University of Liverpool,

P.O. Box 147, L69 7ZT Liverpool, UK

E-mail:gg07@liv.ac.uk

Tel.: + 44-151-7942843

Fax: + 44-151-7942866

R. W. Stroud

Department of Geography, SoGAER, University of Exeter,

Amory Building, Rennes Drive, EX4 4RJ Exeter, UK

S. D. Turner

Environmental Change Research Centre, University College

London, 26 Bedford Way, London WC1H 0AP, UK
} 


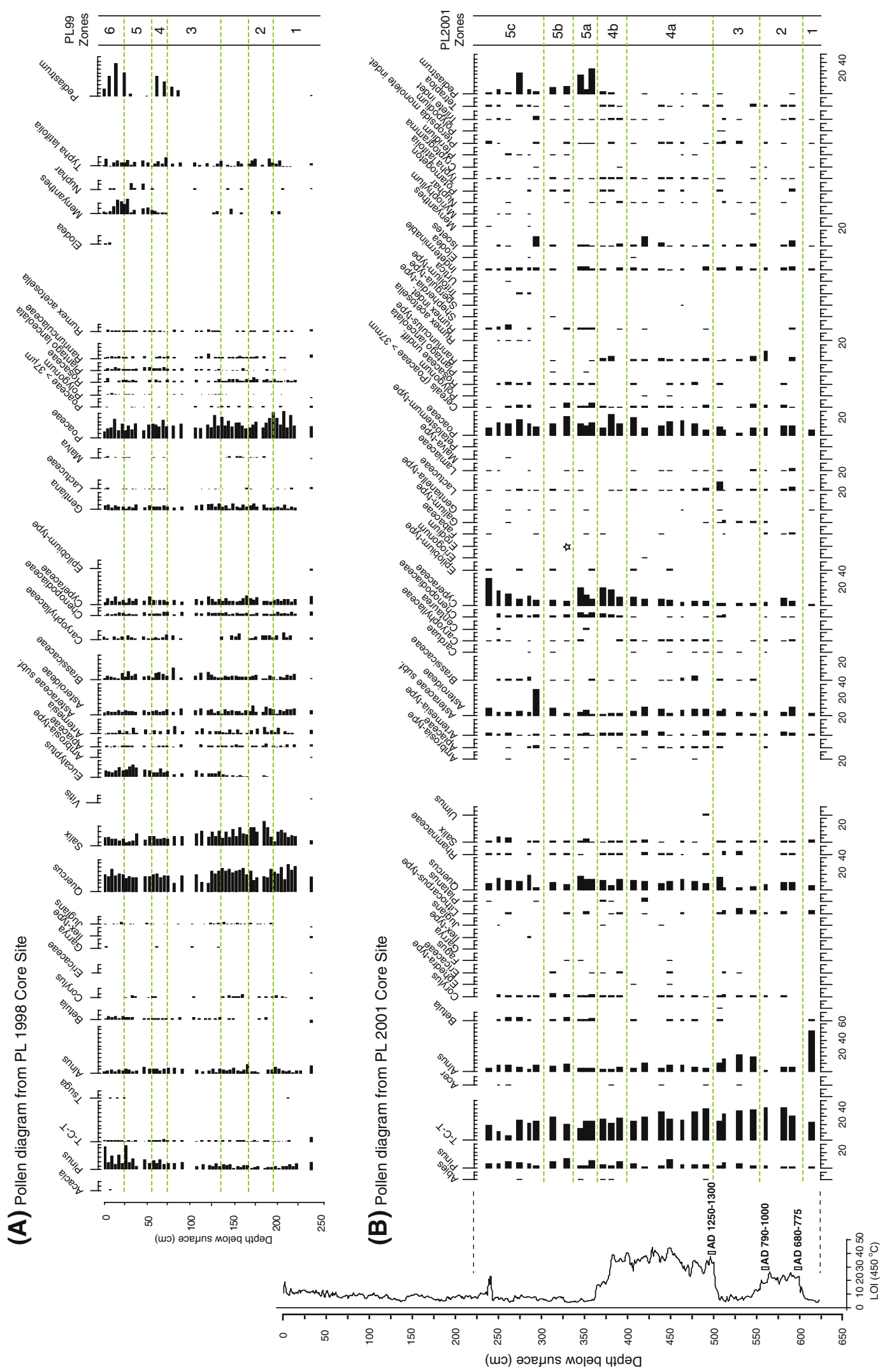

Fig. 2 Composite pollen diagram (PL1998 and PL2001) and LOI curve. Pollen concentrations are expressed as relative percentages of total land pollen for trees, shrubs and herbs, and relative percentages of total land pollen and aquatics for aquatics. The star shown on the PL2001 pollen diagram denotes the presence of Erodium cicutarium at $328 \mathrm{~cm}$ 